\title{
Not All Calories in Foods are the same
}

\author{
Kaufui V Wong* \\ Department of Mechanical and Aerospace Engineering, College of Engineering, USA
}

Received: August 24, 2017; Published: September 11, 2017

*Corresponding author: Kaufui v Wong, Professor, Department of Mechanical and Aerospace Engineering, College of Engineering, Miami, USA, Tel: (305) 284-3314, Email: kwong@miami.edu

\begin{abstract}
The title of this work is worth discussion and research, perhaps with a conference for multidisciplinary professionals in mind.For an engineer or a physical scientist not trained in the biological sciences, it may come across as a statement that defies the definitions of science. The title may come through more as a marketing statement, to draw readers to the article. It may also cause confusion among the general population. That foods come in at least 5 broad categories, viz. fruits, vegetables, carbohydrates, proteins and fats, may give a hint that there is real substance in the statement. A mini literature review is made on the subject matter. A few deductions about venturing out of the recommendations by the U.S. Food and Drug Administration (USFDA) are made that could be useful for weight loss purposes.
\end{abstract}

Keywords: Kilocalories; Proteins; Carbohydrates; Fat; Fruits; Vegetables

Abbreviations: USFDA: U.S. Food and Drug Administration; STEM: Science, Technology, Engineering and Mathematics

\section{Introduction}

"Not all calories in foods are the same" is a sentence which intrigued me as long as I had heard it, together with the reliability of the USFDA and its daily dietary recommendations. The 'reliability' part is easy to see, since the population of the United States of America (USA) is one of the most obese among the nations in the world. Before going into how the title of the current article is interesting, let us get into how the USFDA is involved. Every five years, the USFDA updates its recommendations regarding people's daily diets for health. The latest [1] in 2015, created quite a stir because at long last, the agency removed the limits of consumption on total fats $[2,3]$. There is no separation of men from women for people in general, just listing them as belonging to different categories depending on the calories one requires based on one's daily activities and metabolism. In addition, there was the usual categorization based on age (over 2 years old), up to and including those who are over 14 years old. In addition, there is the focus on the daily plate, rather than the old 'food pyramid'.

Even for the 'STEM (Science, Technology, Engineering and Mathematics)' educated many in the USA, hearing the statement that not all calories are the same seems more than a little naughty. However, if an engineer (for instance) stops a while, and remembers that the human body can best be approximated as a biochemical machine, it becomes clearer. 100 grams of protein is metabolized in a much different manner from a 100 grams of carbohydrates or 100 grams of fat. The metabolic (mechanical and mainly biochemical) pathways for protein (e.g. chicken, fish) are less efficient than the metabolic pathways for fat and carbohydrates. In other words, the portion of calories available for work from consumption of proteins is much less than the amount available from consumption of an equivalent amount of fat or carbohydrates. More heat energy is generated when proteins are consumed. In the current work, 1000 calories is written as 1 Calorie or 1 kilocalorie. In [1], the notation 'calorie' is used. In the literature, the notation used by the current work is normal. The approximate budget for a grown adult is around 2000 Calories to 3000 Calories. This fact is good to bear in mind when referring to citations like [1].

\section{Background}

The calorific effect of food is a count of how much different foods increase energy outflow, owing to the energy needed to digest, absorb and break down the nutrients [4]. Besides fruits and vegetables, the calorific effect of different macronutrients [5] is approximately as follows:
a. Fat: $2-3 \%$.
b. Carbohydrates: 6-8\%.
c. Protein: $25-30 \%$.

Different research sources vary on the exact numbers, but it is clear that protein requires much more energy to metabolize than fat and carbohydrates [6]. For discussion purposes, if we go along with a calorific effect of $25 \%$ for protein and $2 \%$ for fat, this would mean that 100 calories of protein would result in 75 calories, while 
100 calories of fat would result in 98 calories. Consumption of proteins also leads to meaningfully reduced appetite, making you eat less calories inevitably. The studies show that protein is the most fulfilling food group $[7,8]$. If people increase their protein intake, they start losing weight without counting calories or controlling portions. Replacing carbohydrates with proteins can lead one on a fast track to weight loss [9,10].

\section{Healthy Foods and Best Practices for Less Weight Gain}

From [4], it is clear that the minimum amount of unsaturated fats, saturated fats should be about 3 cups a day. This seems to be the case for anyone over 9 years old. The recommendation remains a steadfast 3 cups of 'dairy' for anyone who needs 1600 Calories to 3200 Calories a day. One cup is interpreted as 0.24 liter. Hence, 3 cups of 'dairy' from skimmed milk and low-fat yogurt may be interpreted as 0.72 liter of oils (e.g. olive oil, coconut oil). Since we feel more satiety after consuming proteins and fats, gram for gram, compared to eating carbohydrates, it is deduced that one should max out on proteins and fats from his/her daily plate.

It is best to cut back on carbohydrates (especially refined, white grains) if one aims to lose weight when cutting back on calories. The ratio of vegetables to fruits should roughly be around 2:1 for everyone in general. Salt consumption is recommended to be limited to 2300 milligrams of sodium per day. There is also a limit on added refined sugars to around 25 grams per day. However, it is the recommendation of the current work to limit 'added refined sugars' down to a minimum of zero, if possible.

\section{Discussion and Conclusion}

The USFDA has updated its recommendations on daily diet, with its 2015 pronouncements and associated publications. One can get good clues about losing weight from the USFDA 'Choose My Plate' dietary guidelines. The literature review did reveal that it is well known that proteins lead to satiety, compared with an equal amount of carbohydrates, for instance. Hence, consuming the maximum amount of proteins and oils recommended will be easier for one to follow a daily diet that loses one weight. One should maintain the 2:1 ratio of vegetables consumed to fruits consumed. Fruits in general, tend to contain fructose, which can only be metabolized in one's liver. Excess fructose is not metabolized, but stored as fat layers on top of the liver, leading to the characteristic 'big belly'. Vegetables on the other hand, tend to contain less fructose. Glucose may be assimilated by the body muscles directly. It is recommended to reduce 'added refined sugar' to a minimum of zero, if possible.

\section{Acknowledgment}

This paper is dedicated to all the people in the USA, who have been confused by the many dietary guidelines, several of them contradictory, provided to them. This paper is also dedicated to all other peoples in the world who have been confused in the same manner.

\section{References}

1. Scientific Report of the 2015, Dietary Guidelines Advisory Committee, Los Angeles, California, USA.

2. Mozaffarian D, Ludwig DS (2015) "The 2015 US Dietary Guidelines: Lifting the ban on total dietary fat". JAMA 313(24): 2421-2422.

3. Wong KV (2016) "Optimization of Healthy Fats in One's Daily Diet". EC Nutrition 5.5, pp. 1232-1237.

4. “ChooseMyPlate.com”. USDA, US Department of Agriculture, USA.

5. Jéquier E (2002) Pathways to obesity. International Journal of Obesity 26(2): S12-7.

6. Johnston CS, Day CS, Swan PD (2002) Postprandial thermo genesis is increased $100 \%$ on a high-protein, low-fat diet versus a highcarbohydrate, low-fat diet in healthy, young women. Journal of the American College of Nutrition 21(1): 55-61.

7. Paddon-Jones D, Westman E, Mattes RD, Wolfe RR, Astrup A, et al. (2008) Protein, weight management, and satiety. The American journal of clinical nutrition 87(5): 1558S-61S.

8. Halton TL, Hu FB (2004) The effects of high protein diets on thermogenesis, satiety and weight loss: a critical review. Journal of the American College of Nutrition 23(5): 373-385.

9. Skov AR, Toubro S, Rønn B, Holm L, Astrup A (1999) Randomized trial on protein vs. carbohydrate in ad libitum fat reduced diet for the treatment of obesity. International Journal of Obesity \& Related Metabolic Disorders 23(5): 528-536.

10. Claessens M, Van Baak MA, Monsheimer S, Saris WH (2009) The effect of a low-fat, high-protein or high-carbohydrate ad libitum diet on weight loss maintenance and metabolic risk factors. International journal of obesity 33(3): 296-304.

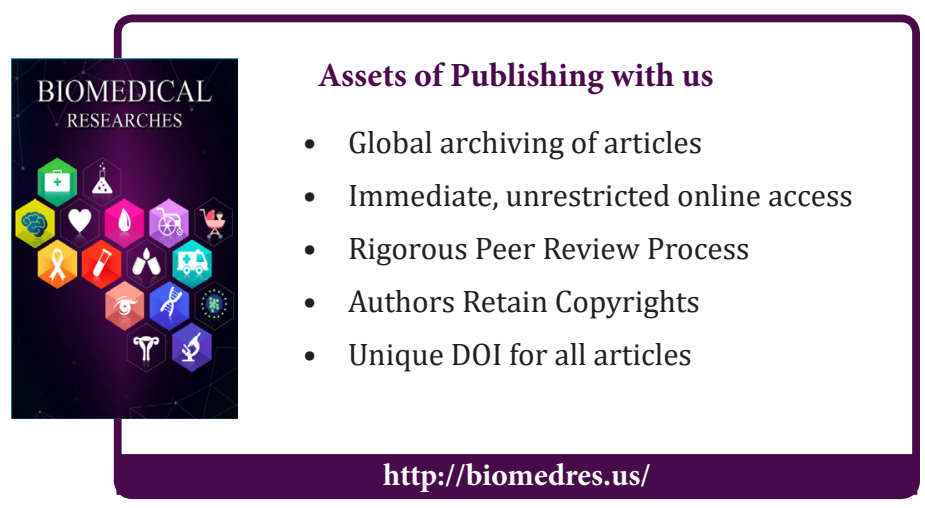

